Case Report

\title{
CMV Colitis in Immunocompetent Patients: 2 Cases of a Diagnostic Challenge
}

\author{
Maria Paparoupa, ${ }^{1}$ Viola Schmidt, ${ }^{1}$ Helgard Weckauf, ${ }^{2}$ Huy Ho, ${ }^{1}$ and Frank Schuppert ${ }^{1}$ \\ ${ }^{1}$ Department of Gastroenterology, Endocrinology, Diabetology and General Medicine, Klinikum Kassel, \\ Mönchebergstraße 41-43, 34125 Kassel, Germany \\ ${ }^{2}$ Institute of Pathology, Klinikum Kassel, Mönchebergstraße 41-43, 34125 Kassel, Germany
}

Correspondence should be addressed to Maria Paparoupa; maria.paparoupa@yahoo.com

Received 10 February 2016; Accepted 29 March 2016

Academic Editor: Olga I. Giouleme

Copyright (C) 2016 Maria Paparoupa et al. This is an open access article distributed under the Creative Commons Attribution License, which permits unrestricted use, distribution, and reproduction in any medium, provided the original work is properly cited.

CMV infections are generally thought to be opportunistic by immunosuppression. Many literature cases though indicate that $\mathrm{CMV}$ infections can be also observed in immunocompetent patients. We present an unusual case of an extensive concentric benign stenosis due to CMV colitis and a case of coexistence with Crohn's Disease, both observed in nonimmunosuppressed individuals. The right diagnosis was set after implementation of multiple unsuccessful treatment strategies. Our purpose is therefore to familiarize clinicians involved with the diagnosis and treatment of gastroenterological diseases with this entity.

\section{Introduction}

CMV infections are generally thought to be opportunistic in patients with immunosuppressive diseases like HIV/AIDS, underlying malignancies, and organ- or bone marrow-transplantation and patients under treatment with chemotherapeutics or steroids [1-4]. However a rapidly rising number of literature cases worldwide indicate that CMV infections can be also observed in immunocompetent individuals, causing primarily gastrointestinal manifestations, like ulcerative colitis, pseudopolyps, or tumors, and ischemic and hemorrhagic enterocolitis [5-9]. The first case reporting verification of CMV colitis in an immunocompetent patient was published in 1992 [10]. Since then, particular underlying conditions are linked with a high risk of CMV colitis in apparently nonimmunocompromised patients, like chronic renal insufficiency and hemodialysis, aging, coinfection with bacterial gastrointestinal infections, and food allergy [11-19]. A notable connection between CMV colitis and colitis ulcerosa stands out in the literature [20-25], while only a single reported case correlates the first one with Crohn's Disease [26]. We present an unusual case of a persistent benign colon stenosis due to CMV colitis and a case of coexistence with Crohn's
Disease, both observed in nonimmunosuppressed individuals. The right diagnosis was set after rigorous diagnostic procedures and implementation of multiple unsuccessful treatment strategies.

\section{Cases Description}

A 77-year-old man presented to our Department of Gastroenterology with subileus symptoms and blood spots on his stool. COPD and laparoscopic cholecystectomy several years ago were reported as his medical history. A partial colonoscopy revealed multiple sigma diverticula with signs of inflammation and the patient was treated with oral mesalazine (Salofalk Granu-Stix $2000 \mathrm{mg}$ /day) and antibiotics (ceftriaxone and metronidazole) for 2 weeks, leading to discrete relief of his symptoms. Two months later a control colonoscopy was performed; edema and erythema of mucosa were not present any more, but a persisting stenosis $40 \mathrm{~cm}$ from anus was almost occluding colon lumen (Figure 1). The colonoscope could not be advanced beyond the mass. All sigma diverticula presented unobtrusively and new biopsies were taken from the stenosis site. Histologic analysis confirmed a chronic inflammatory mucosal alteration and 


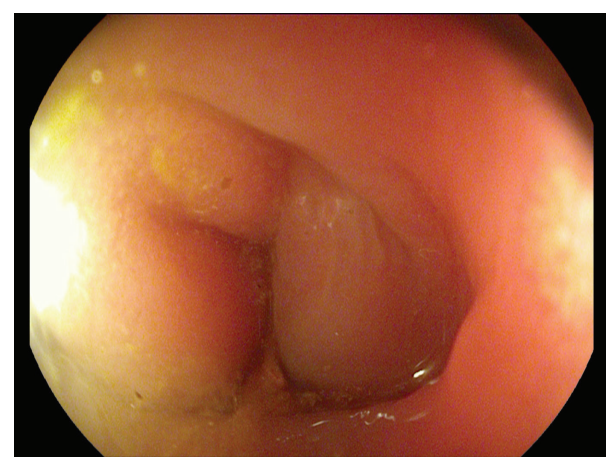

FIgURE 1: Persisting stenosis $40 \mathrm{~cm}$ from anus almost occluding colon lumen. The colonoscope could not be advanced beyond the mass.

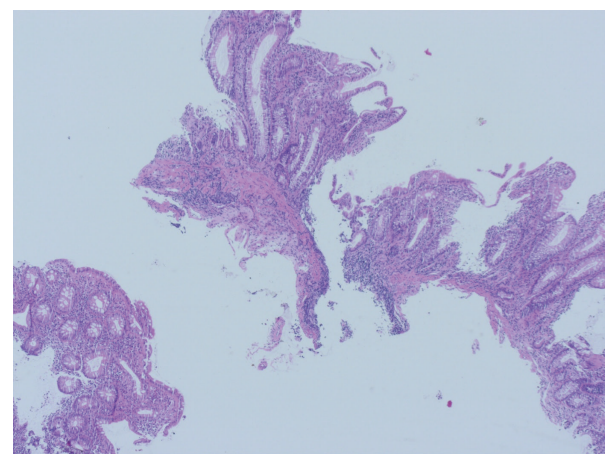

FIGURE 2: Light microscopy presenting biopsies of colonic mucosa with chronic inflammation and disorders of mucosal architecture $(\mathrm{H}$ \& $\mathrm{E}, 100 \mathrm{x})$

lymphofollicular hyperplasia of submucosa compatible with diverticula-associated colitis (Figures 2 and 3). By unclear distinctive stenosis of colon lumen and histological signs of chronic inflammation, atypical manifestation of IBD (inflammatory bowel disease) was hypothesized and immunosuppressive therapy with steroids was initiated, without clinical response. As last step of our diagnostic strategy, we performed serological and microbiological tests, in order to exclude gastrointestinal pathogens. Surprisingly, CMV-IgM Titer was positive and CMV-IgG Titer found greater than $200 \mathrm{RE} / \mathrm{mL}$. After receiving this result, antiviral treatment with ganciclovir (Cymevene $600 \mathrm{mg} /$ day) was initiated. A month later colon stenosis was slightly detectable and patient's subileus symptoms were no more present (Figure 4).

In the second case, a 66-year-old man with Crohn's Disease in remission complained about diffuse abdominal pain, diarrhea, and weight loss starting 2 weeks ago. A high colonoscopy revealed multiple ulcerative lesions and hemorrhagic colitis leading to the diagnosis of acute Crohn's Disease exacerbation (Figure 5). We initiated immunosuppression with corticosteroids, with no clinical response, and then escalated to azathioprine. In the control colonoscopy, several days under immunosuppressive treatment, endoscopic findings remained unchanged (Figure 6).

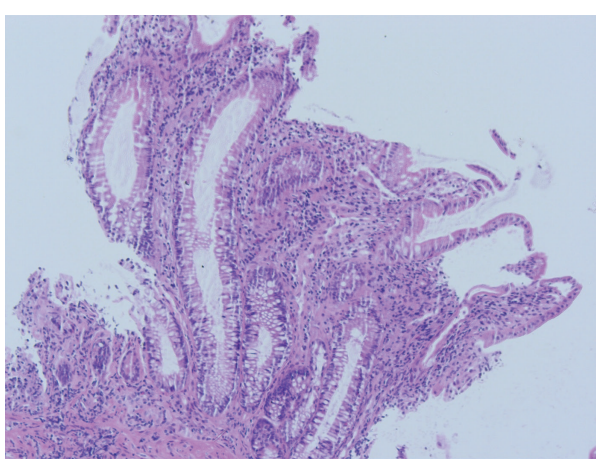

FIgURE 3: Histologic picture 2 in higher analysis (H \& E, 200x).

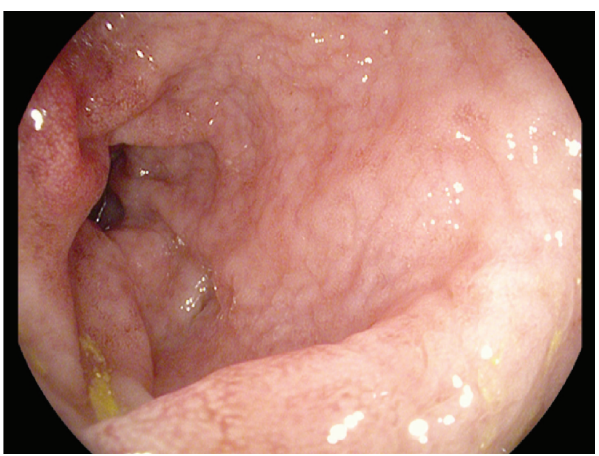

FIGURE 4: Colon stenosis slightly detectable in control colposcopy one month later.

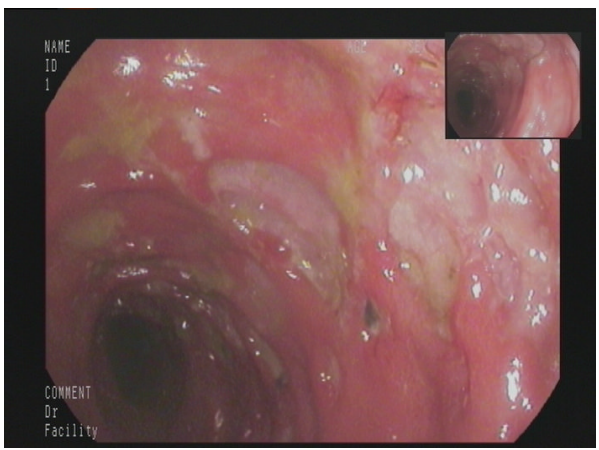

FIGURE 5: Multiple ulcerative lesions and hemorrhagic colitis.

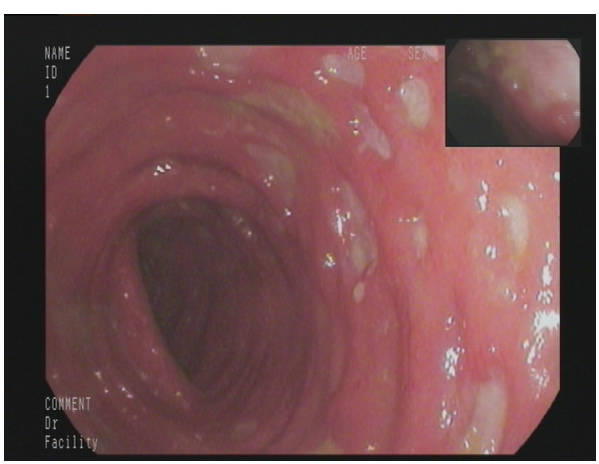

FIGURE 6: Endoscopic findings remained unchanged despite immunosuppressive therapy. 


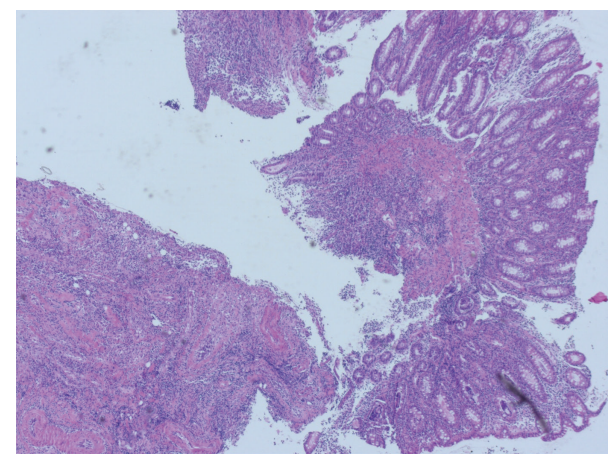

FIGURE 7: Highly active inflammation of colonic mucosa with an ulcerative lesion on the bottom of the picture ( $\mathrm{H} \& \mathrm{E}, 100 \mathrm{x})$.

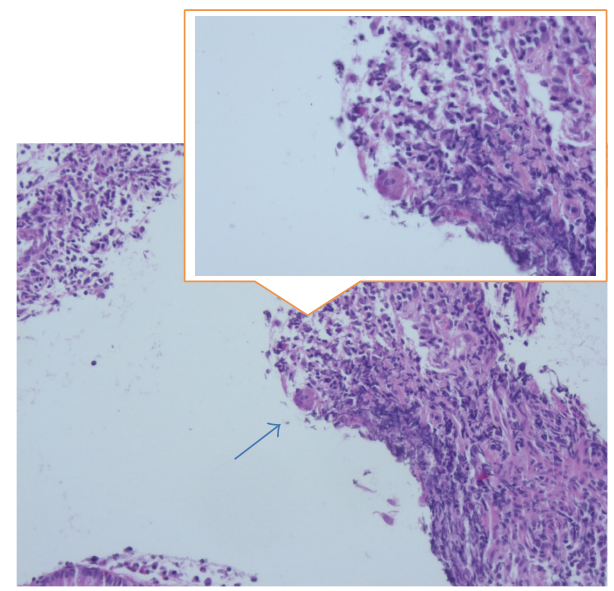

FIGURE 8: Virus infected cell at the edge of an ulcerous defect, known as "owl eye" cell, marked with an arrow and detailedly shown in the window (H \& E, 400x).

A new course of multiple step colon biopsies was conducted; multiple deeply reaching ulcers and lymphoid aggregates in the submucosa were detected (Figure 7). After a rigorous microscopic examination of histological samples, a typical intracellular inclusion of CMV virus known as "owl eye" was surprisingly detected on the border line of an ulcerative lesion (Figure 8). Elevation of CMV-IgM and IgG Titer in serum confirmed the diagnosis of CMV colitis and our patient was treated with intravenous ganciclovir (10 $\mathrm{mg} / \mathrm{kg} /$ day), leading to complete clinical remission.

\section{Discussion}

These are two unusual cases of CMV colitis, manifested in immunocompetent patients, who presented to our Department for Internal Medicine and Gastroenterology over the last year. In both cases, patient symptoms and endoscopic findings imitated other more common conditions, like sigma diverticulitis and acute exacerbation of Crohn's Disease. This was the main reason for the delayed diagnosis. The implementation of multiple unsuccessful therapeutic strategies forced us to search further, without actually having CMV colitis in mind. In both cases the right diagnosis was set incidentally after positive CMV serology or typical histologic finding of "owl eye" cell. Our purpose is therefore to awaken clinicians involved with the treatment of gastroenterological diseases on the entity of CMV colitis in nonimmunocompromised patients.

In the first case, CMV colon infection presented as a persisting stenosis, which was initially almost occluding colon lumen. A similar case of an extensive colonic stenosis due to CMV colitis has been already described from Novakova et al. [27] in a 2-month-old immunocompetent male, infected via breast milk. In this case, stenosis was persisting after antiviral therapy and corticosteroids were initiated. Our patient showed no clinical response under steroids, but healed after antiviral therapy. According to literature reports, colonic occlusion due to CMV infection can be so severe and persistent that surgical removal is the ultimate therapeutic option [28]. However, inflammatory hyperplastic tissue forms more frequently pseudopolyps or tumor masses and not an extensive concentric benign stenosis like in our case and is mostly observed in immunocompromised compared to in immunocompetent patients [5, 6, 29-31].

The second case presented with multiple ulcerative lesions and hemorrhagic mucosa in a patient with known Crohn's Disease in remission. Clinical manifestations and endoscopic findings were compatible with acute Crohn's Disease exacerbation, but immunosuppressive treatment was unsuccessful. Shahani reported a case where diagnosis of Crohn's Disease followed the diagnosis of CMV colitis, as extraintestinal manifestations of IBD complicated the clinical course and antiviral therapy failed to improve the gastrointestinal symptoms of the patient [26]. According to scientific literature, CMV colitis can induce an acute exacerbation of IBD in remission [24] or complicate preexisting active and more often steroids refractory colitis flare [28]. In conclusion, CMV infection should be ruled out in patients with IBD exacerbation before starting immunosuppression and, on the contrary, IBD should be suspected in immunocompetent patients with CMV colitis.

\section{Consent}

Patients' informed consent is available.

\section{Competing Interests}

The authors declare that they have no competing interests.

\section{References}

[1] B. Salzberger, G. Fätkenheuer, A. Schwenk et al., "Foscarnet and ganciclovir combination therapy for CMV disease in HIVinfected patients," Infection, vol. 22, no. 3, pp. 197-200, 1994.

[2] D. J. C. Ramsey and S. A. Schey, "Cytomegalovirus colitis after autologous transplantation for multiple myeloma," British Journal of Haematology, vol. 110, no. 4, pp. 894-896, 2000.

[3] T. L. Lemonovich and R. R. Watkins, "Update on cytomegalovirus infections of the gastrointestinal system in solid organ transplant recipients," Current Infectious Disease Reports, vol. 14, no. 1, pp. 33-40, 2012. 
[4] C. Polprasert, C. Wongjitrat, and N. Wisedopas, "Case report: severe CMV colitis in a patient with follicular lymphoma after chemotherapy," Journal of the Medical Association of Thailand, vol. 94, no. 4, pp. 498-500, 2011.

[5] A. S. Vegunta, S. K. Dasar, S. K. Joshi, and R. V. Rao, "Spontaneous partial vanishing cytomegalovirus pseudotumour of colon in an immunocompetent patient," Journal of Clinical and Diagnostic Research, vol. 9, no. 8, pp. TD07-TD09, 2015.

[6] A. Agaimy, J. Mudter, B. Märkl, and R. Chetty, "Cytomegalovirus infection presenting as isolated inflammatory polyps of the gastrointestinal tract," Pathology, vol. 43, no. 5, pp. 440-446, 2011.

[7] Z. Naseem, R. Hendahewa, M. Mustaev, and G. Premaratne, "Cytomegalovirus enteritis with ischemia in an immunocompetent patient: a rare case report," International Journal of Surgery Case Reports, vol. 15, pp. 146-148, 2015.

[8] T. Hasegawa, K. Aomatsu, M. Nakamura, N. Aomatsu, and K. Aomatsu, "Cytomegalovirus colitis followed by ischemic colitis in a non-immunocompromised adult: a case report," World Journal of Gastroenterology, vol. 21, no. 12, pp. 3750-3754, 2015.

[9] A. Rankin, K. Cuthill, M. Subesinghe, and D. Goldsmith, "Lifethreatening rectal bleeding due to cytomegalovirus colitis in a haemodialysis patient," NDT Plus, vol. 2, no. 3, pp. 239-241, 2009.

[10] S. D. Blair, A. Forbes, and R. A. Parkins, "CMV colitis in an immunocompetent adult," Journal of the Royal Society of Medicine, vol. 85, no. 4, pp. 238-239, 1992.

[11] S.-H. Kim, W. S. Kim, H. W. Kim et al., "A case of cytomegalovirus colitis in an immunocompetent hemodialysis patient," Hemodialysis International, vol. 15, no. 2, pp. 297-300, 2011.

[12] A. R. Farah Musa, T. Fülöp, K. Kokko, B. Kanyicska, J. R. Lewin, and É. Csongrádi, "Cytomegalovirus colitis in a critically ill, dialysis-dependent, acute kidney injury patient without immunosuppressive therapy," Clinical Nephrology, vol. 84, no. 1, pp. 44-49, 2015.

[13] M. R. Lockwood, J. Liddle, and P. Kitsanta, "Cytomegalovirus colitis-an unusual cause for diarrhoea in an elderly woman," Age and Ageing, vol. 35, no. 2, pp. 198-200, 2006.

[14] B. Fleischer, J. Morgenthaler, G. Tippel, A. Kuhfus, U. Gieseler, and M. Stolte, "Cytomegalovirus-induced colitis in an immunocompetent old patient," Medizinische Klinik, vol. 101, no. 10, pp. 835-838, 2006.

[15] T.-N. Chau, L.-K. Lau, K.-C. Lee, M.-L. Kwok, S.-T. Lai, and H. Yuen, "Association of self-limited cytomegalovirus colitis and shigellosis in an immunocompetent patient," European Journal of Gastroenterology and Hepatology, vol. 8, no. 8, pp. 819-822, 1996.

[16] M. Kurtz and M. Morgan, "Concomitant Clostridium difficile colitis and cytomegalovirus colitis in an immunocompetent elderly female," BMJ Case Reports, Article ID bcr2012007273, 2012.

[17] I. M. Dumitru, E. Dumitru, G. Resul, L. Curtali, S. Paris, and S. Rugina, "Concomitant CMV and Clostridium difficile colitis in an immunocompetent patient treated with Ganciclovir and fecal transplantation," Journal of Gastrointestinal and Liver Diseases, vol. 23, no. 2, pp. 221-222, 2014.

[18] T. W. Jonkhoff-Slok, R. H. Veenhoven, E. R. de Graeff-Meeder, and H. A. Büller, "An immunocompetent infant with cow's milk allergy and cytomegalovirus colitis," European Journal of Pediatrics, vol. 156, no. 7, pp. 528-529, 1997.
[19] J.-H. Ko, K. R. Peck, W. J. Lee et al., "Clinical presentation and risk factors for cytomegalovirus colitis in immunocompetent adult patients," Clinical Infectious Diseases, vol. 60, no. 6, pp. e20-e26, 2015.

[20] M. Maté del Tío, J. M. Peña Sánchez de Rivera, J. Larrauri Martínez, M. C. Garcés Jiménez, and F. J. Barbado Hernández, "Association of cytomegalovirus colitis and the 1st episode of ulcerative colitis in an immunocompetent patient," Gastroenterología y Hepatología, vol. 19, no. 4, pp. 206-207, 1996.

[21] C. Rachima, E. Maoz, S. Apter, M. Thaler, E. Grossman, and T. Rosenthal, "Cytomegalovirus infection associated with ulcerative colitis in immunocompetent individuals," Postgraduate Medical Journal, vol. 74, no. 874, pp. 486-489, 1998.

[22] M. Kraus, C. Meyenberger, and W. Suter, "Generalised intestinal CMV infection with protein losing syndrome in ulcerative colitis," Schweizerische Medizinische Wochenschrift, vol. 130, no. 43, pp. 1600-1605, 2000.

[23] K. L. Streetz, T. Buhr, H. Wedemeyer et al., "Acute CMV-colitis in a patient with a history of ulcerative colitis," Scandinavian Journal of Gastroenterology, vol. 38, no. 1, pp. 119-122, 2003.

[24] N. S. Malhi, D. K. Bhasin, N. M. Gupta, K. Vaiphei, and K. Singh, "Exacerbation of ulcerative colitis by cytomegalovirus infection in an immunocompetent Indian patient," Tropical Gastroenterology, vol. 23, no. 2, pp. 88-90, 2002.

[25] S. Yangzhen, K. Liu, T. Xu, Y. Yang, and Y. Zhang, "Synchronous onset of CMV colitis and ulcerative colitis in an immunocompetent patient: a case report," West Indian Medical Journal, 2015.

[26] L. Shahani, "CMV infection complicating the diagnosis of Crohn's disease in an immunocompetent patient," BMJ Case Reports, 2012.

[27] V. Novakova, K. Hamprecht, A. M. Müller, J. Arellano-Galindo, M. Ehlen, and G. Horneff, "Severe postnatal CMV colitis with an extensive colonic stenosis in a 2-month-old male immunocompetent term infant infected via breast milk," Journal of Clinical Virology, vol. 59, no. 4, pp. 259-263, 2014.

[28] T. Nakamura, R. Nakamura, K. Maruyama et al., "Refractory ulcerative colitis complicated by a cytomegaloviral infection requiring surgery: report of a case," Surgery Today, vol. 34, no. 1, pp. 68-71, 2004.

[29] S. Kawasaki, S. Osawa, K. Sugimoto et al., "Cecal vanishing tumor associated with cytomegalovirus infection in an immunocompetent elderly adult," World Journal of Gastrointestinal Oncology, vol. 2, no. 11, pp. 417-420, 2010.

[30] A. Maiorana, P. Torricelli, F. Giusti, and N. Bellini, "Pseudoneoplastic appearance of cytomegalovirus-associated colitis in nonimmunocompromised patients: report of 2 cases," Clinical Infectious Diseases, vol. 37, no. 5, pp. e68-e71, 2003.

[31] A. De Jesus, S. A. Grossman, and O. Paun, "Cytomegalovirus associated colonic pseudotumor: a consequence of iatrogenic immunosuppression in a patient with primary brain tumor receiving radiation and temozolomide," Journal of NeuroOncology, vol. 94, no. 3, pp. 445-448, 2009. 


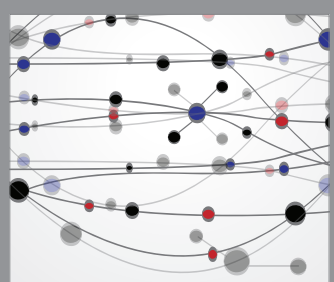

The Scientific World Journal
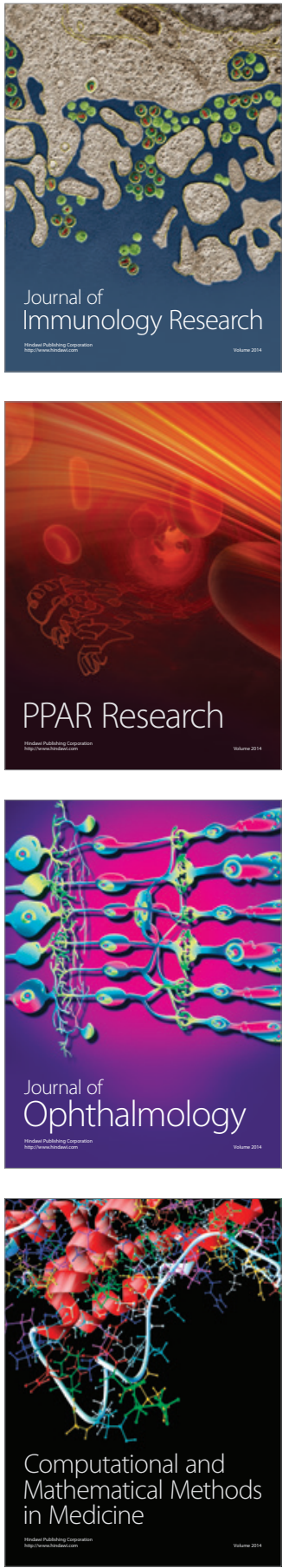

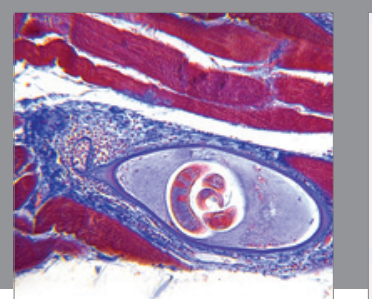

Gastroenterology Research and Practice

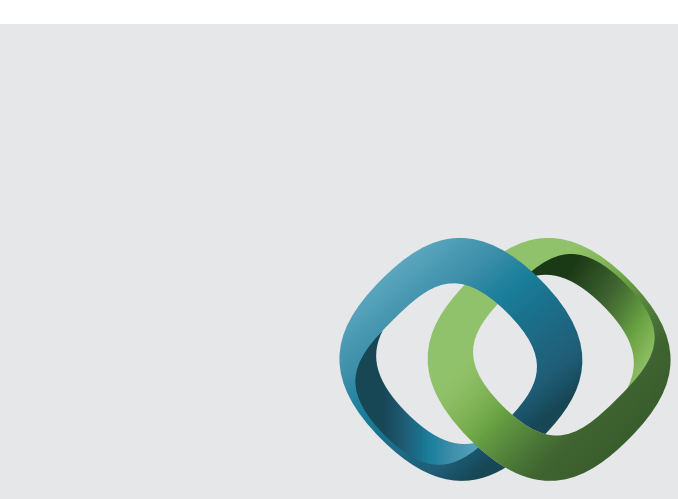

\section{Hindawi}

Submit your manuscripts at

http://www.hindawi.com
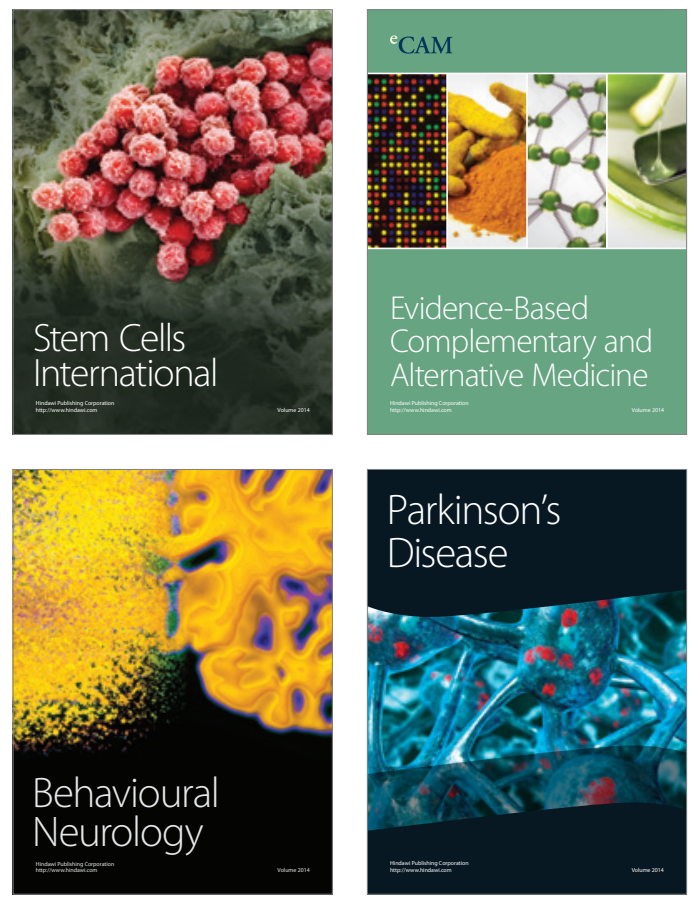
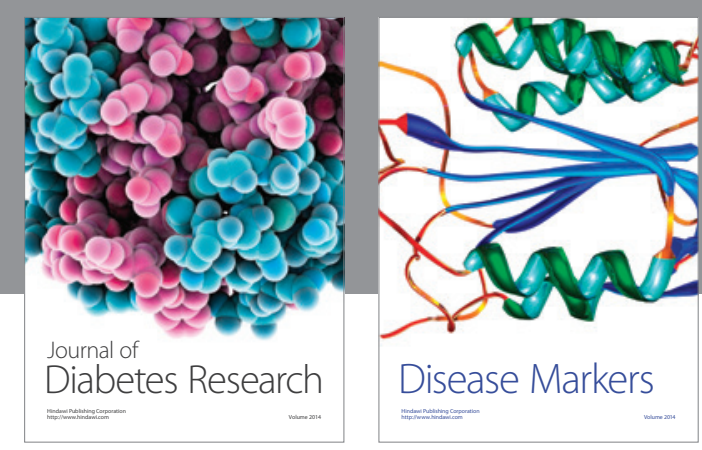

Disease Markers
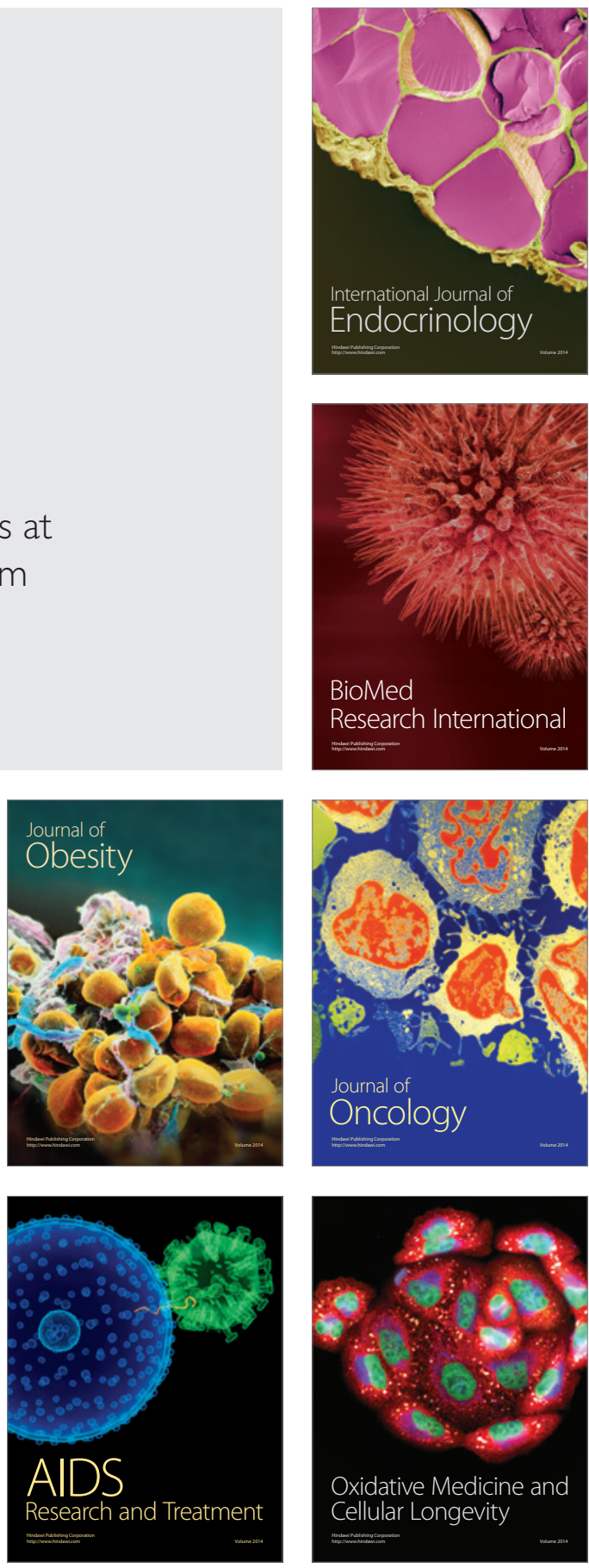